\title{
Adenoid hypertrophy is a common finding in children with antrochoanal polyp
}

\author{
Mosaad Abdel-Aziz ${ }^{*}$, Ahmed Nassar and Omar Sabry
}

\begin{abstract}
Background: Many nasal pathological findings have been described with antrochoanal polyp (ACP). We aimed in this study to assess the prevalence of adenoid hypertrophy among children presented with ACP and to evaluate the efficacy of concomitant adenoidectomy on the outcome of endoscopic removal of the lesion.

Results: Forty-three children with ACP were included in this study. Preoperative nasal endoscopy and computed tomography were performed for all patients. Endoscopic sinus surgery (ESS) with widening the maxillary ostium was used for removal of ACP in all patients. Associated nasal pathology was recorded and managed accordingly. The patients were followed up for at least 3 years postoperatively. Coexistent nasal pathology with ACP was detected in 39 patients (90.7\%); adenoid hypertrophy was found to be the commonest concomitant lesion (83.7\%). Adenoidectomy was performed during ESS for those who had adenoid hypertrophy. Postoperatively, no patients developed adenoid regrowth; however, recurrence of ACP was detected in five patients (11.6\%).

Conclusion: Adenoid hypertrophy is a common pathological finding in children presented with ACP. Endoscopic removal of ACP with concomitant adenoidectomy is an effective procedure and has a favorable outcome.
\end{abstract}

Keywords: Antrochoanal polyp, Adenoid hypertrophy, Adenoidectomy, Endoscopic sinus surgery

\section{Background}

Antrochoanal polyp (ACP) is a benign soft tissue lesion protruding from the maxillary antrum to the nasal cavity and usually passes from the choana to the nasopharynx. It is usually unilateral and more common in children than in adults, constituting about $35 \%$ of pediatric nasal polyps [1, 2]. Its exact cause is unknown; however, chronic inflammation and allergy have been accused [2]. Indeed, several studies reported that chronic inflammation rather than allergy play a role in the etiology [3]. Chronic inflammation may cause acinar mucus gland obstruction with the formation of mucus retention cyst, with consequent obstruction of the maxillary sinus ostia by the medial surface of this cyst; so, the retention cyst may herniate towards the middle meatus through the accessory ostium due to increased pressure within the antrum [4].

\footnotetext{
* Correspondence: mosabeez@hotmail.com

Department of Otolaryngology, Faculty of Medicine, Cairo University, Cairo, Egypt
}

The adenoid has been implicated in pediatric chronic rhinosinusitis as it harbors bacteria within biofilms [5]. Also, it causes nasal obstruction that may induce mucus retention in the paranasal sinuses, which in turn may lead to microbial colonization and subsequent mucosal inflammation [6]. Hypertrophied adenoid has been noted to be present in some patients with ACP; it might impair mucociliary clearance of sinus cavities leading to different inflammatory changes [2, 6]. The aim of our study was to assess the prevalence of adenoid hypertrophy among children presented with ACP and to evaluate the efficacy of concomitant adenoidectomy on the outcome of endoscopic removal of the lesion.

\section{Methods \\ This retrospective study was conducted on 43 children diagnosed to have ACP. The study included all patients below the age of 18 years who underwent endoscopic sinus surgery (ESS) for removal of ACP between July 2014 and June 2018 in our institute. The ages of the}

\section{SpringerOpen}

(c) The Author(s). 2021 Open Access This article is licensed under a Creative Commons Attribution 4.0 International License, which permits use, sharing, adaptation, distribution and reproduction in any medium or format, as long as you give appropriate credit to the original author(s) and the source, provide a link to the Creative Commons licence, and indicate if changes were made. The images or other third party material in this article are included in the article's Creative Commons licence, unless indicated otherwise in a credit line to the material. If material is not included in the article's Creative Commons licence and your intended use is not permitted by statutory regulation or exceeds the permitted use, you will need to obtain permission directly from the copyright holder. To view a copy of this licence, visit http://creativecommons.org/licenses/by/4.0/. 
patients ranged from 4 to 16 years (with a mean of 11.5 years), 26 males and 17 females. Patients who underwent previous surgical intervention for removal of their ACP and who missed the follow-up were excluded from the study. The protocol of this study was approved by the institutional Research Ethics Committee.

Medical history was obtained from the patients' files. Preoperative nasal endoscopy was performed for all patients to confirm the diagnosis of ACP and to detect any associated pathology. The procedure was done with a $0^{\circ}$ Hopkins of $2.7 \mathrm{~mm}$ nasal endoscope (Karl Storz, Tuttlingen, Germany). Adenoid size was assessed from the non-diseased side; it was graded as I-IV according to the degree of choanal obstruction by the adenoid tissue [7]. Also, computed tomography (CT) on the nose and paranasal sinuses in coronal and axial cuts was used as a routine preoperative investigation.

ESS was used for removal of ACP in all patients. During the procedure, wide middle meatal antrostomy was created by enlarging the maxillary ostium. The ACP was delivered through the nose as en bloc mass except if the nasopharyngeal portion was large and could not be passed through the choana, so the sinonasal part was removed trans-nasally and the nasopharyngeal part was removed trans-orally by grasping it by Luc's forceps after opening the mouth with Boyle-Davis mouth gag. A $30^{\circ}$ and $70^{\circ}$ nasal endoscopes (Karl Storz, Tuttlingen, Germany) were used to explore the maxillary sinus with removal of ACP pedicle using angled forceps. Associated nasal pathology was recorded and managed accordingly. Adenoid was removed conventionally using curettage technique, and the nasopharynx was inspected with a $0^{\circ}$ Hopkins $4 \mathrm{~mm}$ nasal endoscope (Karl Storz, Tuttlingen, Germany) after the procedure to ensure complete removal. The maxillary sinus cavity was irrigated with saline, and then the nose was packed with merocele (Medtronic, USA).

The patients were discharged from hospital in the same operative day. Oral antibiotics were received for 1 week. The nasal pack was removed after $48 \mathrm{~h}$ on the outpatient clinic. The parents were instructed to do daily saline irrigation for the operated side of their children for at least 1 month. Follow-up was carried out for 3 years on a monthly-based visit on the first year, and then every 3 months for 2 years. Postoperative assessment was achieved using both subjective method through parental questionnaire and objective method using a $0^{\circ}$ Hopkins of $2.7 \mathrm{~mm}$ nasal endoscope for nasal examination.

\section{Results}

Forty-three children with ACP were enrolled in this study; the lesion was located on the right side in 24 patients and on the left side in 19 patients. The most frequent symptom was bilateral nasal obstruction (95.3\%), followed by snoring/sleep apnea (88.4\%). Coexistent nasal pathology with ACP (Table 1) was detected in 39 patients (90.7\%); adenoid was found to be the commonest concomitant pathology (Figs. 1 and 2). Adenoid size was found to be grade I in 7 patients, grade II in 12 patients, grade III in 15 patients, and grade IV in 2 patients.

Endoscopic treatment was performed for all patients. The ACP was delivered totally through the nose as en bloc mass in 34 patients (Fig. 3), whereas it was removed in two pieces in 9 patients as the nasopharyngeal part was impacted. Concomitant pathological findings were managed after removal of the ACP.

Within the follow-up period, recurrence of ACP was detected in five patients. However, no patients developed recurrence within the first year, three patients within the second year, and two patients within the third year postoperatively. Three of those patients had concomitant pathological findings with the ACP preoperatively, one had adenoid hypertrophy, and two had deviated septum. However, ESS was performed for those children with uneventful outcome. No patients developed adenoid regrowth within the follow-up period.

\section{Discussion}

Inflamed edematous mucosa of the maxillary sinus is the origin of the ACP. The lesion passes through the maxillary sinus ostium to the nasal cavity and usually extends to the nasopharynx [3]. Nasal obstruction and discharge are the commonest presenting symptoms. It appears as a unilateral bright, white, mass in the middle meatus and nasal cavity, with a stalk emerging from the accessory ostium. Sometimes, the polyp is seen on oral examination as white egg shape mass behind the soft palate [4, 8]. Its exact cause is unknown; however, the disease is more frequently seen in children and young adults [3].

Table 1 Preoperative characteristics: symptoms (A) and coexistent pathological findings $(B)$

\begin{tabular}{lll}
\hline & Preoperative characteristics & Number (\%) \\
\hline A & Bilateral nasal obstruction & $41(95.3)$ \\
& Unilateral nasal obstruction & $2(4.7)$ \\
& Bilateral nasal discharge & $28(65.1)$ \\
Unilateral nasal discharge & $6(13.9)$ \\
Snoring/sleep apnea & $38(88.4)$ \\
Headache & $4(9.3)$ \\
Epistaxis & $1(2.3)$ \\
Adenoid hypertrophy & $36(83.7)$ \\
& Ethmoiditis & $9(20.9)$ \\
& Deviated septum & $6(13.9)$ \\
Inferior turbinate hypertrophy & $5(11.6)$ \\
Concha bullosa & $2(4.6)$ \\
\hline
\end{tabular}




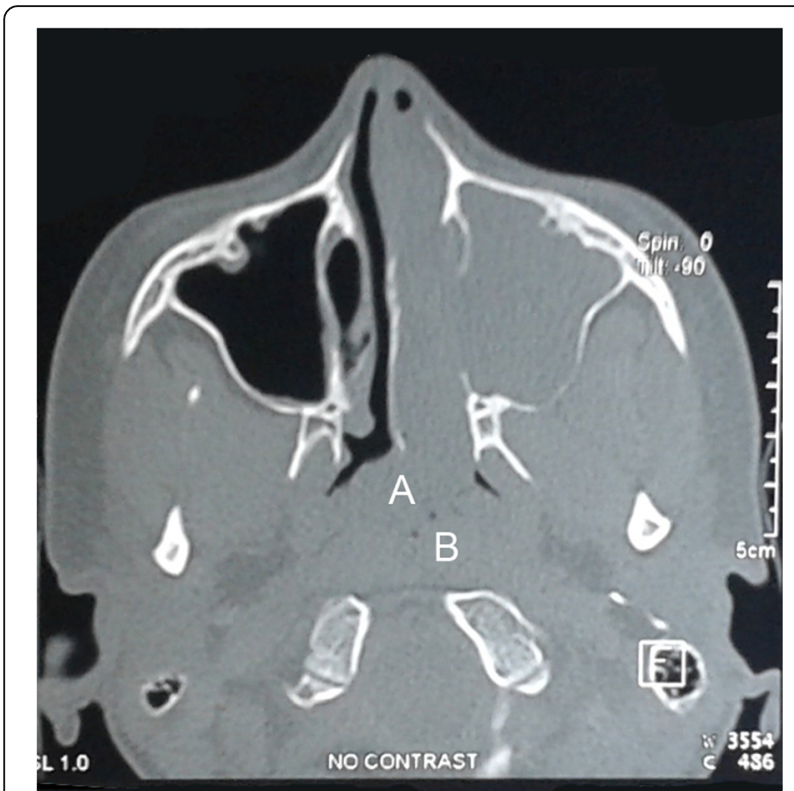

Fig. 1 Axial CT cut shows the antrochoanal polyp (A) extending from the maxillary antrum to the nasopharynx with adenoid hypertrophy (B)

Many studies reported nasal pathology that concomitantly associated with ACP; such as septal deviation, uncinate process alteration, inferior turbinate hypertrophy, concha bullosa, ethmoiditis, and adenoid hypertrophy [3, $4,9,10]$. Those concomitant pathological changes may cause obstruction of the ostiomeatal complex either direct or indirect secondary to inflamed nasal mucosa that may in turn results in increased pressure of the maxillary sinus leading to herniation of the sinus mucosa into the nasal cavity, mostly through the accessory ostium $[2,4]$.

In this study, we retrospectively reviewed 43 children with ACP. The lesion was diagnosed with endoscopic and radiologic examination of nose and sinuses. Concomitant pathological findings were detected in 39 patients; the commonest was adenoid hypertrophy which was found in $83.7 \%$. Bilateral nasal obstruction and snoring/sleep apnea were the most frequent complaints which may be attributed to the presence of adenoid hypertrophy with the ACP. Pagella et al. [2] detected nasal obstruction, followed by obstructive sleep apnea as the most common symptoms among children with ACP. They found adenoid hypertrophy in $24 \%$ and septal deviation in $31 \%$ of their patients. Eladl and Elmorsy [9] found adenoid hypertrophy in 4 (33.3\%) out of their 12 patients, and El-sharkawy [11] detected adenoid hypertrophy in $4(11.1 \%)$ out of 36 of his patients. However, the age of our patients was younger than the patients' age reported in those mentioned studies, which may explain the high incidence of adenoid hypertrophy in our patients.

We performed conventional adenoidectomy after endoscopic removal of the ACP with widening of the maxillary ostium. Also, we inspected the nasopharynx endoscopically to ensure complete adenoid removal. The patients were followed-up for 3 years. No patients developed adenoid regrowth. However, we detected recurrence of $\mathrm{ACP}$ in five out of 43 patients, with a rate of $11.6 \%$. Ozdek et al. [8] treated 10 children with ACP; they found recurrence in two patients who were treated with trancanine sinuscopy to remove the pedicle of the polyp. El-sharkawy [11] treated 36 children with ACP, and Lee et al. [1] treated 27 children with ACP; in both studies, the authors found recurrence in about $11 \%$ of their patients who had been treated with revision ESS. However, Kizil et al. [12] achieved a low recurrence rate (7.7\%) on using ESS in addition to mini Caldwell-Luc procedure for some patients. To decrease the recurrence rate, most authors recommended removal of the ACP pedicle inside the antrum, widening the maxillary ostium, and treatment of associated nasal pathology.

To the best of our knowledge, the relation between adenoid hypertrophy and the occurrence of ACP has not
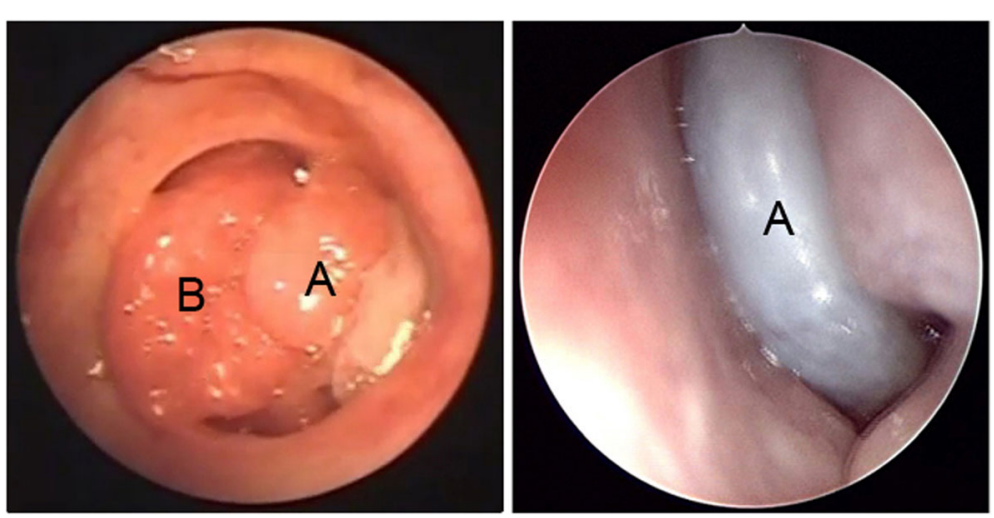

Fig. 2 Endoscopic view for the left nasal cavity shows antrochoanal polyp (A), and endoscopic view for right nasal cavity shows the polyp (A) and adenoid hypertrophy (B) 


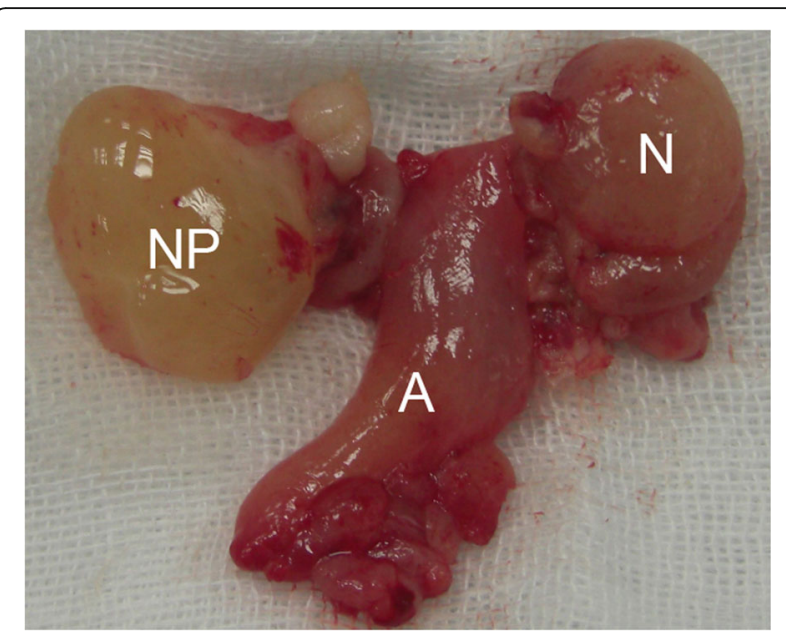

Fig. 3 A removed antrochoanal polyp: A, the antral part; N, the nasal part; NP, the nasopharyngeal part

been investigated in the literature before. However, many authors have reported that chronic inflammation of the maxillary sinus mucosa may be the trigger for formation of ACP [2,3]. This inflamed mucosa may be caused by nasal obstruction with stagnant mucus secretion. Adenoid hypertrophy being the commonest cause of nasal obstruction in children $[5,13]$ may explain its common association with ACP in pediatric age group. Indeed, to confirm this suggestion, we should perform a radiological screening for children presented with adenoid hypertrophy to find out the maxillary sinus changes. Also, we should follow-up those patients after adenoidectomy to detect the fate of these pathological changes.

Berg et al. [14] suggested that ACP may arise from an antral cyst which is caused by acinar mucous gland obstruction secondary to inflammatory or allergic etiology; they found no histological difference between the antral cyst and ACP. Also, Piquet et al. [15] reported that these cysts may be caused by lymphatic obstruction following mucosal inflammation of the sinus. However, $8-10 \%$ of the population may have maxillary antral cyst especially children; it may emerge from dental channels through which the permanent teeth have migrated [14, 16]. Herniation of this antral cyst to the nasal cavity may be caused by the gradual increase of its size by the effect of the inflammatory process, till occupying the whole sinus cavity [17]. Once the polypoid mucosa emerged from the sinus ostium, it is dragged posteriorly to the choana by the effect of active nasal breathing, as the adenoid has been proved to have a significant impact on the development of pediatric chronic rhinosinusitis [18], and an antral cyst is a common pediatric pathological finding [16]; so, it is not unusual to encounter both lesions together.
Our study has some limitations that should be addressed; we did not use polysomnographic examination in the assessment of obstructive sleep apnea as the device may not be tolerated by young children. Also, assessment of adenoid size was performed via the nondiseased side of the nose; however, the nasopharynx was occupied by the ACP that may displace the adenoidal tissue affecting accurate assessment.

\section{Conclusion}

Adenoid enlargement is a common pathological finding in children presented with ACP. Endoscopic removal of $\mathrm{ACP}$ with concomitant adenoidectomy is an effective procedure and has a favorable outcome.

\section{Abbreviations \\ ACP: Antrochoanal polyp; ESS: Endoscopic sinus surgery; CT: Computed tomography}

\section{Acknowledgements}

Not applicable.

\section{Authors' contributions}

MA analyzed and interpreted the patients' data. OS organized the patients' sheets and was a major contributor in writing the manuscript. AN collected the references of the study and revised them after finishing the manuscript. All authors read and approved the final manuscript.

\section{Funding}

Nil.

\section{Availability of data and materials}

The data of this study are available at the corresponding author upon request.

\section{Declarations}

Ethics approval and consent to participate

The study was approved by the Ethics Committee of Kasr Alaini Hospital of Cairo University with approval number [21702R]. Informed written consent to participate in the study was provided by the parents of all participants (children).

\section{Consent for publication}

Not applicable.

\section{Competing interests}

The authors have no conflicts of interest to declare.

Received: 16 July 2021 Accepted: 18 August 2021

Published online: 22 September 2021

\section{References}

1. Lee DH, Yoon TM, Lee JK, Lim SC (2016) Difference of antrochoanal polyp between children and adults. Int Pediatr Otorhinolaryngol 84:143-146. https://doi.org/10.1016/j.ijporl.2016.03.004

2. Pagella F, Emanuelli E, Pusateri A, Borsetto D, Cazzador D, Marangoni R, Maiorano E, Zanon A, Cogliandolo C, Ciorba A, Pelucchi S (2018) Clinical features and management of antrochoanal polyps in children: cues from a clinical series of 58 patients. Int J Pediatr Otorhinolaryngol 114:87-91. https://doi.org/10.1016/j.ijporl.2018.08.033

3. Kelles M, Toplu Y, Yildirim I, Okur E (2014) Antrochoanal polyp: clinical presentation and retrospective comparison of endoscopic sinus surgery and endoscopic sinus surgery plus mini-Caldwell surgical procedures. J Craniofac Surg 25(5):1779-1781. https://doi.org/10.1097/SCS.0000000000000901

4. Frosini P, Picarella G, De Campora E (2009) Antrochoanal polyp: analysis of 200 cases. Acta Otorhinolaryngol Ital 29(1):21-26 
5. Neff $L$, Adil EA (2015) What is the role of the adenoid in pediatric chronic rhinosinusitis? Laryngoscope 125(6):1282-1283. https://doi.org/10.1002/lary.2 5090

6. Arnaoutakis D, Collins WO (2011) Correlation of mucociliary clearance and symptomatology before and after adenoidectomy in children. Int J Pediatr Otorhinolaryngol 75(10):1318-1321. https://doi.org/10.1016/.j.jporl.2011.07.024

7. Cassano P, Gelardi M, Cassano M, Fiorella ML, Fiorella R (2003) Adenoid tissue rhinopharyngeal obstruction grading based on fiberendoscopic findings: a novel approach to therapeutic management. Int J Pediatr Otorhinolaryngol 67(12):1303-1309. https://doi.org/10.1016/j.jporl.2003.07.018

8. Ozdek A, Samim E, Bayiz U, Meral I, Safak MA, Oguz H (2002) Antrochoana polyps in children. Int J Pediatr Otorhinolaryngol 65(3):213-218. https://doi. org/10.1016/S0165-5876(02)00153-2

9. Eladl HM, Elmorsy SM (2011) Endoscopic surgery in pediatric recurrent antrochoanal polyp, rule of wide ostium. Int J Pediatr Otorhinolaryngol 75(11):1372-1375. https://doi.org/10.1016/j.jporl.2011.07.029

10. Galluzzi F, Pignataro L, Maddalone M, Garavello W (2018) Recurrences of surgery for antrochoanal polyps in children: a systematic review. Int J Pediatr Otorhinolaryngol 106:26-30. https://doi.org/10.1016/j.jporl.2017.12.035

11. El-sharkawy AA (2013) Endoscopic management of paediatric antrochoanal polyp: our experience. Acta Otorhinolaryngol Ital 33:107-111

12. Kizil Y, Aydil U, Ceylan A, Uslu S, Baştürk V, lleri F (2014) Analysis of choanal polyps. J Craniofac Surg 25(3):1082-1084. https://doi.org/10.1097/SCS. 0000000000000543

13. Gerber ME, Kennedy AA (2018) Adenoidectomy with balloon catheter sinuplasty: a randomized trial for pediatric rhinosinusitis. Laryngoscope 128(12):2893-2897. https://doi.org/10.1002/lary.27270

14. Berg O, Carenfelt C, Silfversward C, Sobin A (1988) Origin of the choanal polyp. Arch Otolaryngol Head Neck Surg 114(11):1270-1271. https://doi. org/10.1001/archotol.1988.01860230064025

15. Piquet JJ, Chevalier D, Leger GP, Rouquette I, Leconte-Houcke M (1992) Microchirurgie endo-nasale du polype antrochoanal. Acta Otorhinolaryngol Belg 46(3):267-271

16. Berg O, Carenfelt C, Sobin A (1989) On the diagnosis and pathogenesis of intramural maxillary cysts. Acta Otolaryngol Stockh 108(5-6):464-468. https:// doi.org/10.3109/00016488909125554

17. Cherrabi K, Touihem N, Nakkabi I, Nadour K (2021) Bilateral antrochoanal polyps: a case report. Egypt J Otolaryngol 37(1):30. https://doi.org/10.1186/ s43163-021-00090-0

18. Belcher R, Virgin F (2019) The role of the adenoids in pediatric chronic rhinosinusitis. Med Sci 7(2):35. https://doi.org/10.3390/medsci7020035

\section{Publisher's Note}

Springer Nature remains neutral with regard to jurisdictional claims in published maps and institutional affiliations.

\section{Submit your manuscript to a SpringerOpen ${ }^{\circ}$ journal and benefit from:}

- Convenient online submission

- Rigorous peer review

- Open access: articles freely available online

- High visibility within the field

- Retaining the copyright to your article

Submit your next manuscript at $\boldsymbol{\nabla}$ springeropen.com 